\title{
Managing Expectations: Impacts of Hostile Migration Policies on Practitioners in Britain, Denmark and Sweden
}

\author{
Victoria Canning
}

check for

updates

Citation: Canning, Victoria. 2021. Managing Expectations: Impacts of Hostile Migration Policies on

Practitioners in Britain, Denmark and Sweden. Social Sciences 10: 65 . https: / / doi.org/10.3390/ socsci10020065

Academic Editor: Linda Briskman

Received: 17 December 2020

Accepted: 5 February 2021

Published: 10 February 2021

Publisher's Note: MDPI stays neutral with regard to jurisdictional claims in published maps and institutional affiliations.

Copyright: (C) 2021 by the author. Licensee MDPI, Basel, Switzerland. This article is an open access article distributed under the terms and conditions of the Creative Commons Attribution (CC BY) license (https:/ / creativecommons.org/licenses/by/ $4.0 /)$.
School for Policy Studies, University of Bristol, Bristol BS8 1TZ, UK; victoria.canning@bristol.ac.uk

\begin{abstract}
The acknowledgement that asylum systems across Europe are "hostile environments" for migrant groups has increased in academic and practitioner consciousness, particularly in the aftermath of the 2015 refugee reception crisis. However, although the impacts of socio-political hostilities on migrants are well documented, little has been written about the implications of border restrictions on practitioners working with refugee populations. This article expands the focus of hostilities to consider the variable impacts of intensified bordering practices on this group. Based on qualitative research which included 74 interviews undertaken across Britain, Denmark, and Sweden (2016-2018), it outlines the experiences of practitioners working with refugee populations. It highlights that increasingly restrictive or punitive approaches to immigration have had multiple negative effects on practitioners working in this sector. This has potential for longer term negative impacts on practitioners, but also-importantly-refugee populations who require various forms of legal aid, or social and psychological support.
\end{abstract}

Keywords: asylum policy; counselling; law; refugees; trauma

\section{Introduction}

Working with refugee groups can be a fundamentally complex vocation. Although roles in this sector vary considerably (such as lawyers, psychologists, or advocacy and support workers), the lived experiences of people seeking asylum or living as refugees can impact on the people supporting them in a multitude of ways. Likewise, the working conditions of practitioners can be reflected in the standard of care or services that they are able to offer when supporting people with complex lives, refugees and survivors of violence and persecution in particular. This is made particularly difficult when the landscape of refugee rights becomes unstable and ever-changing, an outcome of internationalised constant, ever tightening immigration and asylum laws in receiving states.

Vicarious trauma and compassion fatigue are two of the most cited problems in working in this area. The former relates to emotional or psychological distress based on hearing or responding to trauma experienced by others (Barrington and Shakespeare-Finch 2013). The latter refers to the emotional implications which can develop for people working at the frontline of response to trauma or other social problems but feel restricted in their ability to do so due to exhaustion or burnout (Ray et al. 2013).

This article focuses on the perspectives of practitioners $(n 74)$ working with people seeking asylum in Britain ${ }^{1}$, Denmark and Sweden, recorded from 2016 to 2018. Interviews reveal a concerning addition to the above problems: increasingly restrictive or punitive approaches to immigration have had multiple negative effects on practitioners working in this sector. Indeed, one stark issue highlighted through interviews with lawyers, psychologists, detention custody officers, and support workers is that they felt their ability to effectively perform their own role well has been compromised. Some indicated increasing levels of stress and, in Sweden in particular (a strong state centric welfare model),

1 The project did not include Northern Ireland as a research site and thus refers to Britain. However, the United Kingdom (UK) is referred to when discussing national statistics or practices which include all Four Nations of the UK. 
a decreased faith in the state and state decisions. Terms such as "powerless" and "stress" were often included in responses to questions about the impacts of escalated restrictions in asylum - in particular, that practitioners did not feel they could support people seeking asylum whilst they are being held in an indefinite state of uncertainty or crisis.

Alongside the obvious cause for concern for the wellbeing and mental health of practitioners, this trend carries the potential a secondary but, as I will argue, serious issue. That is, if practitioners are increasingly negatively impacted by restrictions in policy and their ability to work well under changing conditions decreases, then this will negatively impact on the people seeking asylum who require their support or care. Given the already evident barriers in accessing legal, psychological or social support for this group, in particular for survivors of violence (Baillot et al. 2014; Baillot and Connelly 2018; Emejulu and Bassel 2017; Jobe 2009), then compounding these difficulties likely means we are at the edge of a precipice in exercising and administering crucial forms of support for some of the people who most need them, an issue already arising in the context of the current COVID-19 pandemic (Nisanci et al. 2020). Practitioners and those working in state and NGO sectors were increasingly affected by the wider political environment. As this article will outline, as increasingly punitive measures were taken regarding the control of migrants to and within the case study countries, practitioners were less enabled to undertake their roles well. This compounded a sense of powerlessness, and diminished faith in the value of their roles.

\section{Methodology}

This article focuses on findings from a two-year research project investigating social harms in asylum systems across Britain, Denmark and Sweden, funded by the Economic and Social Research Council (ESRC) (2016-2018). This research has been organised around a case study approach, focusing on three Northern European countries with varyingrapidly changing - approaches to immigration. As Flyvbjerg (2006) argues, case studies facilitate generalisability of social issues whilst allowing for the value of in-depth analysis in specific localised areas. This project adopted case study analyses in these countries for three reasons: firstly, to draw in a qualitative intersectional approach in looking to the micro impacts of meso and macro structures and political decisions; secondly, to allow for in-depth policy analysis and consideration of each socio-political context of the countries included-all with varying dominant socio-economic structures; and thirdly, to gain insight into best practice so that it might be shared across the countries and broader regions.

The study incorporated 74 in-depth semi-structured interviews with psychologists, support workers, detention custody officers, lawyers, advocacy workers and other such social actors working with people seeking asylum in the three case study countries (Britain: $n 23$; Denmark, $n 21$; Sweden: $n 30^{2}$ ). The objective of the study was to explore state and organizational responses to women seeking asylum, and investigate women's experiences of the asylum process in relation to harmful practices which may have gendered consequences. Participants were recruited through purposive sampling initially directed at relevant institutions and organisations working with people seeking asylum in state and NGO capacities, and snow-ball sampling within organisations once some contacts had been established. This has been supplemented with over $500 \mathrm{~h}$ of ethnographic activist research with women seeking asylum during this period, as well as in-depth oral histories with six women seeking asylum. Interview responses were coded using NVivo 8 and analysed from an interpretive perspective (Mason 2002), read literally first and then deconstructed in relation to wider literature and the socio-structural and political context from which they responded. It is important to note, however, that themes were also informed by the longer-term participation with practitioners, activists and women seeking asylum, through

2 The original quota for interviews was 20 per country. However, Sweden in particular exceeded this, likely due to the surge in recruitment for staffing immigration detention centres, support organisations and Migrationswerket, which is responsible to processing asylum claims. 
which I was enabled to focus on aspects of the process which can otherwise be invisibilised or determined as a "by-product" of asylum systems.

The broader research findings around the impacts of borders on of women seeking asylum have been published elsewhere (Canning 2018, 2019a, 2019b, 2020a, 2020b, 2021). A key objective of the study was to examine harmful practices which impact negatively impact on women, including survivors of violence, and explore what strategies and forms of support were in place to address or mitigate such harms. However, from early in the project it became clear that, although my focus in interviews with practitioners was on state and organisational responses to women seeking asylum, respondents were secondarily interested in discussing the impacts of this environment on themselves and their colleagues. Whilst the very nature of semi-structured interviews means that discussion can deviate from the primary objectives of study (Delamont 2003; Denzin 2008), this particular project adhered to key principles of grounded theory (Charmaz 2003) in that the conversations drove nuanced findings which were unintended outcomes of discussion. Having researched with practitioners for more than a decade, personal experience or opinions are seldom far from the figurative table. However, during this project-directly undertaken in the aftermath of Europe's refugee reception crisis and as policy and legislation were becoming ever more restrictive (particularly in Denmark and Sweden, as the UK context was already stricter) - the discourse amongst interviewees was systematically connected to the wider political context, which was then drawn back to everyday personal and work-related circumstances.

As such, having coded issues relating to gendered harms in the various asylum systems from an interpretive perspective, as outlined above, I revisited practitioner responses in late 2018 and began to analyse nodes previously coded under "Impacts on Worker" before identifying which correlated with definitions of burn-out, vicarious trauma and compassion fatigue, as defined in the introduction. Subsequently, this left space to consider which experiences did not fall into these narrow categories. By applying critical discourse analysis (Fairclough et al. 2011; Machin and Mayr 2015) when revisiting each interview, I was then able to establish patterns which indicated impacts on practitioners that stem from wider socio-political landscapes, rather than only from working with people living complex lives, with often complex or violent histories. This article will focus on the former issues as drawn from the interviews, before examining in more depth the impacts of politics, policy and legislation on the ability - or perceived inability - to undertake one's role effectively. Importantly, whichever role participants held in the asylum and refugee sector, all 74 respondents alluded to issues arising which affected their ability to undertake their role effectively.

\section{Findings}

As will be highlighted in the Discussion section later, the findings in the article are situated within a broader comprehension of the project overall, specifically in exploring policies and practices which directly or indirectly harm women seeking asylum across the three countries. This section, however, focuses on five key themes which emerged from coding and subsequent critical discourse analysis of interviews with practitioners. These qualitative findings are as follows:
a. Restrictive asylum law and policy negatively impacts on the role of practitioners;
b. Emotional and psychological issues in working with refugee groups are compounded by increasingly hostile socio-legal environments;
c. Practitioners report feelings of powerlessness, helplessness and a structural dimin- ishment of their professional roles;
d. Roles are increasingly bureaucratised, and so practitioners report "managing expec- tations" of clients rather than fulfilling their assigned role/profession;
e. Trust in state responses to migration is diminishing. 


\subsection{Restrictive Asylum Law and Policy Negatively Impacts on the Role of Practitioners, or "The Laws Are Making Things Impossible"}

Law and policy can be seen as abstract entities that many of us only come to encounter if we transgress them or are impacted directly by them. The proliferation of immigration laws and the increasingly restrictive forms of control laid out by a plethora of policies has pulled everyday aspects of refugee experiences further into this socio-legal realm, closing the gap between the abstract: the written and the lived experience. For people working in NGO sectors of refugee support, the ever-expanding landscape of asylum law has effectively turned some into ad hoc asylum law "lay experts". Where people may have opted to work in emotional support or advocacy roles rather than in any legal capacity, knowledge of legal and policy changes has forced a landscape that requires some basic level of knowledge of legislation, even when that is not the role of the organisation or of the individual.

Some practitioners found that changes in legislation or "rules" meant that they constantly had to change their own approaches. As one regional director of a migrant support group in Sweden highlighted:

"When we see the result of the legislation, a lot of volunteers start getting depressed because they meet every day, every time they go to the volunteer meeting, they meet someone who has been denied asylum and they get a feeling of helplessness because you want to do something but you can't do anything."

As I highlight later, such feelings are commonly cited as being directly linked to the socio-political landscape. Rather than emphasising, for example, poor organisational working conditions, it is an externalised hostile environment toward the people they support which disenables them from undertaking their role fully. The feeling of "helplessness" is the entanglement between the structural and meso, and its impact on the micro, on everyday working conditions of people in this area of practice.

A further aspect complicating this is that keeping up to date with the workings of the asylum process is increasingly difficult at a time when laws and policies are changing regularly, and thus affecting the rights or welfare entitlements that people seeking asylum can access. As a sexual violence counsellor working with migrant women in the North West of England outlined: "the Home Office change their laws, rules, all the time. Something new is always changed to make it more difficult, so you learn what you can work around and the next minute its changed, they find it and they stop it." This is an important observation. Using this example, the participant has not trained to be a legal advisor or expert, but a counsellor specialising in the emotional support of survivors of sexual violence. This is in itself a distinguished professional role: it requires not only training in the context of counselling, but specialising in a very niche form of trauma. This is a field of work which requires dedication and-given the violence inherent to such abuses-often heavy emotional labour. However, such roles are increasingly bureaucratised, including (as this example outlines) needing to stay abreast of law and policy.

The culmination of entanglements between the structural, meso and micro dynamics of asylum policy and practice is particularly evident for those whose work is geared to support the wellbeing of refugee groups broadly, and people seeking asylum specifically. The nexus between external controls (macro) and institutional (meso) and personal (micro) objectives to provide "help", was summarised by the coordinator of an international refugee NGO in Sweden, who stated:

"I try to help people but there's no way of helping them, the laws are making things impossible. We can't help people reunite, we can't help people get proper protection, we can't help people ... we can't even help them to be allowed to beg, to have some money to eat for the day, everything is getting harsher and I don't know what to do about it anymore, I'm sad every day." 
This epitomises the impacts of hostile policy and law on practitioners. The reduction in family reunification directly affects the emotional wellbeing of people as they worry about family members who are "stuck" elsewhere (Abdelhady et al. 2020; Khosravi 2018). On her first point, the reduction in the length of time people are able to stay with refugee status means reduced temporal protection, thus affecting the stability people can depend on in the longer term (Canning 2020b). Regarding her second point, at the time of research, debates were developing on introducing a ban on begging in Sweden ${ }^{3}$. Thus, poverty which was being experienced through welfare reductions was seemingly to be compounded by the illegalisation of begging. The process of restrictions was not experienced as abstractas discussed earlier-but as personal and emotionally impactful. In her own words, this practitioner was "sad everyday".

\subsection{Emotional and Psychological Issues in Working with Refugee Groups Are Compounded by Increasingly Hostile Socio-Legal Environments}

This brings me to empirical examples that echo the previous sentiments: the emotional implications of working with refugee populations are compounded by increasingly hostile socio-legal environments. Whilst some of these examples may relate to vicarious trauma, burnout and compassion fatigue, the central emphasis here diverges slightly. Although some practitioners did at times discuss these within these established ontological frameworks, the underlying contributing factor was not only the type of labour, but that barriers have been erected between the participant's form of practice, and being able to effectively provide support or services.

People working in two categories stood out as being emotionally "burnt out": those working in law (barristers, members of the Queen's Counsel, and lawyers) and those providing direct emotional support. To the first group, as one barrister of the Queen's Counsel working in the UK outlined: "the people who have to support and advise generally are burnt out, is the way I'd describe everybody, and demoralized." This statement sets the foundations for other practitioner attitudes and responses, room for all of which is not possible in this one article. However, although she discusses this as a structural issue, the sentiment can be seen to be reflected in the personal. For example, by a barrister working in a similar field who felt: "I find it quite hard, find it quite demoralising, obviously. It's really hard not to take it personally". Although less pronounced in the analysis, similar sentiments were described by lawyers I interviewed in Sweden.

Unlike other forms of work, the often-parallel worlds of law and practice are combined for lawyers and barristers working on asylum cases, since they are inherently intertwined. The political is, for this group, personally impactful. This is not only in their requirement to know and understand fast paced changes in law, but that the job itself is demoralising. The implications of this are not restricted to this for the individual. As the same barrister went on to say: "I just sometimes try to look at it as piles of paper, try and look at it as ways a mechanic would look at a car." The structural conditions under which he-like othersis working was increasing his emotional distance to his clients, and in a way reducing his clients to inanimate objects. Although a harsh prospect, this is an understandable form of armour given high levels of post-traumatic stress disorder amongst lawyers working with traumatised people seeking asylum. Indeed, according to a recent preliminary study with 70 lawyers in the UK, this sat at $51.4 \%$ for those with partial PTSD, and $34.3 \%$ for those with PTSD (Rønning et al. 2020).

To the second group, those working in front facing roles often highlighted experiential memories of emotions when referring to specific service users or historic scenarios. This is similar to other research which concentrates on work with practitioners that requires emotional labour. For example, issues of suicidality or trauma, as a psychologist specialising in war-related trauma in Sweden indicated: "in a sense they [service users] might see us as

\footnotetext{
3 The first regulation banning begging was introduced in Vellinge in Skåne in 2018. This was a contentious and fiercely debated prospect whilst this project was under way. Begging is illegal in the UK under the Vagrancy Act 1824. Further restrictions were placed on begging in Denmark in 2017, leading to a disproportionate arrest of foreign nations (The Local Denmark 2018).
} 
less emotional, which is not the case because we get very affected by what we hear and what we see. We get very much affected [ ... ] what affects me most is the suicidality". However, there remained indications that such negative emotional memories were not only common but were again directly related to increasing hostilities. This was particularly the case in Britain. As one refugee advocacy coordinator recalled on visiting a man released from immigration detention:

"I will never forget, I will never forget ... how broken that man appeared to me when I saw him after four months away from his family, locked up in a prison under threat of being removed, you know? I'll never forget it."

This statement directly links the embodiment of bordered hostilities-the immigration detention centre-with one's own memory, that he will never forget the way this man appeared. Similar sentiments were expressed by a social worker reflecting on visiting a woman seeking asylum:

"For the first time since I have worked in this field I felt as if I was about to cry when I went to the hospital because I've never seen somebody who has been neglected by the system like this woman I come across, because you don't treat people like this, this is unacceptable in 21st century Britain."

The emotional effects of seeing people living in avoidable and degrading circumstances are also clear. Many felt that financial cuts to staffing or services reduced their ability to offer adequate support. As one women's support worker in Scotland indicated, "It really is crippling because we can't meet the needs. Literally turning people away everyday who are in crisis, so that is awful." Shortly after this interview, in 2016, the interviewee contacted me to say their role had been removed.

What we can see as these narratives progress is the emotional impacts of other people's trauma or circumstance, as is common in the refugee support sector. However, on analysis it becomes clear that these are not unique or standalone issues or experiences. Instead, they are intrinsically linked to the structural: they reflect and are reflected by punitive shifts in bordering through law, policy and practice.

\subsection{Practitioners Report Feelings of Powerlessness, Helplessness, and a Structural Diminishment of Their Professional Roles}

As is evident thus far, hostile environments for migrants mean that practitioners can find themselves in positions where they are working within or even implementing conditions they themselves cannot agree with. For example, an employee of a humanitarian organisation working at a refugee reception centre in Denmark, Center Sandholm ${ }^{4}$, which is operated by the Danish Red Cross indicated: "I find it really, really difficult, this neutrality, impartiality concept, and increasingly so. Every time we have to enforce new, stricter rules that have only been put in place to put pressure on people [to leave]." Although the centre is technically open (that is, not a closed immigration detention centre), it is highly regulated and far from the amenities of Copenhagen (see Canning 2013). For people who have opted to work in support capacities, rather than as border agents, there is a conflict in exercising controls that they may not be supportive of.

This sense of bordering in practitioner roles was extended in the UK with regards to healthcare with the introduction of (National Health Service (NHS) 2015) Charging Regulations. Although the NHS has historically been free to all, this opened up financial charges for migrants who required non-urgent healthcare from 2017, as well as facilitating information sharing with the Home Office, the body responsible for overseeing immigration in the UK. As well as breeding a climate of mistrust, this has led to confusion over what is or

\footnotetext{
4 When people seeking asylum first arrive in Denmark they generally have to stay in Center Sandholm, a former military barracks, for weeks or months when they first lodge an application for refugee status. Although officially free to come and go with minor checks at the gate. Mahira, a survivor of domestic abuse and false imprisonment, reflected, "you don't have money and you cannot go out if you don't have money so how do you pay for the bus, for the train? So you cannot go out, you can walk [ ... ] but you cannot go out. You can get a ticket, a bus ticket, a bus pass, only if you have an appointment with your doctor."
} 
is not urgent for many migrants who then feared they would be charged for both migrants and some medical practitioners and thus opening up the potential for development of further avoidable illnesses. This concern was raised in both interviews and in various meetings with NGOs throughout and since the project, epitomised in the St. Mungo's scandal which saw the homeless charity pass information of foreign nationals to the Home office for deportation purposes (Taylor 2018).

However, it is worth noting that concerns were made whilst implementation of the changes was being undertaken. As a mental health support worker in England told me in 2017, the year most changes were embedded, "Today they [clients] were talking about hospitals, hospitals are going to ask for two forms of proof of your identification [ ... ] and the same thing with the Immigration Act, with the housing as well, and landlords and that sort of thing." These creeping forms of surveillance have been the vertebrae of the hostile environment, where increased data-sharing and housing controls have worked to reduce the liberties and rights of migrants. However, as organisations such as Docs Not Cops and Patients Not Passports have been documenting, the implications of this have knock-on effects on health practitioners. Embodying this, the mental health support worker closed by stating, "it really, really saddens me." The impacts are not only social, but evidently draw out emotional consequences for those who are watching the environment deteriorate for the people they are commissioned to support.

As highlighted thus far, emotions such as sadness and despair were conveyed by some participants. For some, the structures and changes within which they were increasingly working, and the pressures which were exacerbated by these, led to a sense of powerlessness. As one psychologist working at a war trauma treatment centre in Sweden indicated, she was "more hopeless and powerless and feelings of [ ... ] ach, whatever we do it's not enough." As with others, discussed later, this participant struggled with the restrictions that had been quickly introduced in 2016, specifically the Temporary Law (as outlined in the introduction-see also Joormann 2019) but specifically the reduction of permanent status offered to refugees:

Interviewee: "They have a temporary residents permit but they're still not safe."

Author: "Does that affect how people can engage in the support you give?"

I: "Yes, it does."

A: "How does that make you feel as a person who works in that area?"

I: "Powerless. Not being able to influence a lot of these things."

It is evident here that the shift to granting only temporary status for refugees reduced the feeling of safety that might otherwise be obtained when temporal trajectories are more definite. Instead, even when application for asylum was granted, this became time restricted rather than indefinite, after which time the person would have to reapply or face deportation. This was also the case across Britain and Denmark, the implications which has been increased uncertainty in the lives of people who strongly require security. The impact of this for practitioners is thus a feeling of powerlessness-one cannot change the legislation under which service users are living, and yet practitioners are well aware of what the consequences of these changes are. Indeed, it is they who witness the consequences first-hand.

3.4. Roles Are Increasingly Bureaucratised, and So Practitioners Report 'Managing Expectations' of Clients Rather than Fulfilling Their Assigned Role/Profession

Practitioners working with survivors of trauma or sexual violence raised concerns about their client's inability to focus on therapy, counselling, or integration programmes due to risk of dispersal or other exacerbations of illnesses. People seeking asylum can be more concerned with pressing issues arising in the immediate future, such as the threat of homelessness, fear of detention or deportation, or concern for family and friends still residing in areas of conflict or migrating across borders. As one social worker supporting refugee families in Denmark summarised in relation to reductions in access to family 
reunification, "how can I work with a family in terms of integration when I know what's going in their head is something that's so much bigger?" In 2016, the ability to access family reunification, usually through the Red Cross, was reduced as Northern European countries sought to externalise the flow of people into the country to reunite with their families. The consequence of this, as the social worker in Denmark pointed out, is that issues which impact individuals on bigger scales become the primary focus, and thus secondary concerns in the present are relegated in terms of urgency to engage. As he went on to argue:

"The best way to elevate or to help with the trauma is to get them a proper life here, without poverty, but the only thing I can give them is trauma treatment where I think maybe I would rather give some of that money actually to them because I think that would have more of a benefit than sitting with a psychologist."

Likewise, an integration project coordinator also working in Denmark argued that, "it will only get worse. I mean there's a culture of celebrating obstacles that we can put in people's place [ ... I I mean unashamedly celebrating making it hard for people to access asylum and protective status." This prediction-recorded in summer of 2018-has proved accurate. By the end of the year the Danish People's Party and the Venstre-led government announced new restrictions in the Finance Act 2019 which directly aim to reduce opportunities for integration of migrants and people seeking asylum and instead push toward deportations and enforced removals (Clante Bendixen 2019). This included changes to permits which mean people will no longer be allowed to stay indefinitely, but will instead be returned at the earliest opportunity. Indeed, at the time of writing, Denmark has recorded its lowest ever number of asylum applications and Prime Minister Mette Frederiksen has announced their goal is to receive "zero" asylum seekers (European Commision 2021). Likewise, another significant change relates to integration, as the term itself is no longer used in relation to asylum, as focus has changed to accelerating deportation. For people working in a deportation centre ${ }^{5}$ in Denmark, there was dismay at the lack of clarity regarding the expectations of their role, and that their participation did not always have a positive impact. As a member of staff at one of Denmark's two deportation centres-who had recently left their job for these reasons-highlighted, "I had days when I went home thinking that today I was definitely a part of the problem, not the solution, today my presence here was a band aid at best but the patient's hemorrhaging and I'm not actually doing what I'm supposed to be doing."

In some places, the limits to the support that practitioners are able to provide are not only affected by economic resources, but also managerial and policy decisions on what is or is not allowed. As one nurse in an immigration detention centre in Sweden reflected, "You want to do more than you are allowed; you are not allowed to." This was reiterated by people working in immigration detention in Denmark, who had roles which overlapped between border control and care provider. As a detention centre governor there indicated:

"It's stressful to work in an environment where you are confronted with people who are deprived of their liberty, whether it's here or it's in a prison, because you have to be able to switch between the comforting role and the consequent officer role in a split second."

For one detention custody officer in a Swedish immigration detention centre, the implications of this were more personal. In identifying the shifts in law and expansion of controls within the centre, they were removing her from the humanitarian approach she had tried to embed in her practice: "they [detainees] assume that I am working for the evil government. They think that I don't see them as human beings, living [ ... ] I think

5 Denmark has two departure centres (udrejsecenter as a formal term meaning departure, or udvisningscentre as it is known to 'residents', meaning deportation). These are Udrejsecenter Sjælsmark in Zealand and Udrejsecenter Kærshovedgård in Mid Jutland. Banality is inscribed as a means to facilitate easier deportation. 
it's horrible." As we can see, even those who are charged with administering confinement raise concerns about the very processes within which they work.

In other fields, and as highlighted earlier, practitioners disclosed feelings of discomfort at increasingly being part of a system or structure that they had not set out to work in. People spoke of their jobs being reduced from support to "managing expectations" (as a refugee casework Coordinator in England described, reiterating a term I have heard repeated over the past 13 years of researching this field). This relates to managing expectations of people seeking asylum, but also of themselves and their colleagues when bureaucratic barrier reduced their capacity to provide support. As a social worker in England reflected, "this is not the social work I came for. It's more for budgets now", emphasising the intensified shift toward managing bureaucracies. In terms of workforce, this experience was arguably generational, in that those who had spent less time working in the sector had no way of comparing what working with refugees may have been like prior to austerity related cuts and increased legal restrictions on migrants. Pinpointing this, a women's asylum support officer in England outlined:

"I've only worked in this sector since the cuts have come in, so I've only ever known this situation where it's now routine to expect that somebody will be dropped by their solicitor before their first appeal. So they have assisted their initial case, the long interview and submitting evidence. Decision comes back negative and the solicitor says, 'We think your case has less than $50 \%$ chance of succeeding, we can't get funding from the legal aid agency.' Bang, that's it, you're on your own."

Although referring to reductions in legal aid in the UK specifically, her experience indicates a worrying potential for setting new norms, where such conditions are no longer exceptional but instead acceptable-a worrying possibility for the future of this sector.

As with other examples outlined in this article, practitioners are increasingly impacted by the barriers presented between the roles they were trained or qualified to do, and the external and internal conditions which prevent them from doing them effectively. Ironically, even those employed by the state or working for organisations that are subsidised by the government were impacted by governmental decisions. As such, even citizens of each of the case study countries were negatively affected by the increasingly hostile environment toward migrants. In short, such hostilities affect society much more broadly than their target migrant demographics.

\subsection{Trust in State Responses to Migration Is Diminishing}

Finally, this research found that impacts on practitioners are exacerbated by increasing mistrust between people seeking asylum and governmental and non-governmental organisations, particularly in Britain and Sweden. As discussed earlier, the sharing of data between healthcare providers and the Home Office in Britain acted as a deterrent to accessing much needed support, and impacted on trust more broadly with support providers. Although this was reduced to the sharing of data in cases of serious criminality, it is unlikely that people seeking asylum will be familiar with this shift, since research indicates that many are not aware of their rights or do not feel comfortable asserting them (Migrant Rights Network 2018).

Practitioners often alluded to a loss of faith in humanitarianism in their respective states. One torture rehabilitation director in Denmark remarked that, "they're testing this unfortunately, a social experiment, how far they can get with their whip", whilst a barrister in England questioned the rationale of governmental agendas, asking, "Even if you accept the premise that migration is a problem and needs to be reduced, why don't you wait to see what the last set of bad laws did before you bring in the next of the bad laws?"

In Denmark and Sweden, two typically state centric nations, the impacts of this increasing mistrust were widely discussed. At the time of research, there was increased policing of previously protected institutions, such as schools, social services and churches. In Sweden, this was strengthened with the introduction of the REVA Project-a collabo- 
ration between Swedish Police, the Migration Agency and prison service which targeted people suspected of living illegally in Sweden so as to sped up detection and deportation. People who organised a local group running free language classes for migrants in Malmö told of increased efforts by police to access the centre to "catch" any possible undocumented migrants, whilst police undertook their first raid of a church for the same reason in 2017. As one asylum lawyer summarised:

"there was some type of rule, an unwritten rule in Sweden that police would not go into social institutions like schools and social health to ask for details where this family is but after this wave and all these new directives from the government, they broke this unwritten rule and are starting to call to social institutions, the social service here, to ask for addresses. And then we have a huge amount of migrants get caught there because they were asking help from the social institutions."

Migrant groups and practitioners are therefore left in precarious positions: anyone without documentation or who is awaiting the outcome of an asylum claim may be subject to arrest and possible detention or deportation, whilst some practitioners simultaneously lose faith in governmental agendas and face reduced capacity to undertake their role due to external pressures.

\section{Discussion: The Challenges of Supporting Refugee Populations within Increasingly Hostile Environments}

Since the 1990s in particular, legislation and policy related to welfare, work and legal support have centralised immigration across Northern Europe. Whilst internalised bordering has long been in train in most European countries 2015 is often cited as a year of increased restrictions, particularly in shifts toward punitive controls across Nordic countries, including Denmark and Sweden (Abdelhady et al. 2020; Barker 2018). Both are historically recognised as being amenable to immigration and refugees-but saw increased restrictions in welfare and rights for immigrants generally, and increased capacity to police and criminalise undocumented migrants and refused asylum applicants. In Denmark, specifically, there has been a move away from integration for people seeking asylum, and significant reductions in the right to remain for refugees (Eule et al. 2018; SuárezKrabbe et al. 2018). In Sweden, the increased policing of undocumented migrants and the introduction of the temporary law since 2016 (Barker 2018; Joormann 2017) has had multiple implications for refugees. These "temporary" changes-prolonged until 2021-have facilitated unprecedented increases in internalised controls. Britain has continuously, seen increased restrictions placed on rights to healthcare, education and housing for EU and non-EU migrants, as well as people seeking asylum, in particular since the 1980s (Aas and Bosworth 2013; Aliverti 2012; El-Enany 2020).

This project overall found that hostile attitudes and environments compound the impacts of loss through migration; violence; torture; and sexual abuse for people seeking asylum (see Canning 2017, 2018, 2019a, 2019b). At the same time, access to social and psychological support are reduced, leaving many people-including survivors of violencein an unsupported limbo, and thus on the periphery of societies. Access to legal aid has been diminishing across all three countries. As with earlier studies, specifically regarding support in the aftermath of violence, various policies were reducing the capacity for people seeking asylum to obtain sustained or meaningful counselling, psychological support or psychotraumatological therapies (Canning 2017). Although at risk of repeating these arguments, it is worth noting that there is a clear correlation between state policies, and the diminishing availability or accessibility of trauma or counselling support for people seeking asylum. For example, social isolation inflicted through dispersal policies in the UK, asylum centres in Denmark and Sweden; or deportation centres in Denmark maintains physical distance that create barriers to accessing various institutions, ranging from education to psychological care (see also Abdelhady et al. 2020; Mayblin 2019). Destitution or poverty reduces opportunities to travel, which are again impacted by state enforced reductions to 
finance and welfare. These reduce the potential for engaging in sustained support, even if the facilities are available in principle.

The focus of this article, however, has been the impacts of hostile immigration policies on the work, lives and experiences of practitioners working with people seeking asylum, specifically in the immediate aftermath of the refugee reception crisis in Europe and increasing correlatory restrictions. There is a long history of counselling and psychology literatures which discuss the impacts of working with refugee populations specifically, and survivors of violence generally (Adams et al. 2006; Galek et al. 2002; Pross 2006; Ray et al. 2013; Rønning et al. 2020). Given that people seeking or who have refugee status do so for reasons relating to persecution, this is a demographic which can be disproportionately affected by conflict, torture, and indeed migration related trauma (Bögner et al. 2010; Fog Olwig 2012; Follette and Duckworth 2012). As such, research indicates that those working within this field risk a likelihood of facing various forms of emotional harm (Girma et al. 2014). This includes vicarious trauma, "an umbrella term commonly used to describe the cumulative, negative psychological effects on workers as a result of hearing the harrowing stories of trauma survivors" (Rønning et al. 2020, p. 1) and secondary trauma. As Rønning et al. (2020) summarise, "the difference between secondary trauma and VT is that secondary trauma can happen suddenly, in one session, while VT is a response to an accumulation of exposure to the pains of others." Other issues which are relatively common to working with people with complex needs more generally includes burnout, symptoms of which include, "apathy, feelings of hopelessness, rapid exhaustion, disillusionment, melancholy, forgetfulness, irritability, experiencing work as a heavy burden, an alienated, impersonal, uncaring and cynical attitude toward clients, a tendency to blame oneself coupled with a feeling of failure" (Pross 2006, p. 1). This can lead to compassion fatigue, itself a result of exhaustion or overexposure to similar or seemingly relentless problems which are often endemic in nature.

However, the findings presented in this article make clear that the context within which practitioners work can cause harm and distress beyond the complexities of working with survivors of persecution or violence. Their experiences are intricately tied to the wider socio-political context, not only in relation to (for example) funding or lack thereof, but because of the impacts of restrictive, increasingly hostile border controls. Indeed, as we can clearly gauge from the words of practitioners, although the impacts of borders are directed at migrant groups, they permeate into the lives and professional experiences of people working with them. This is across sectors which include advocacy and support, as well as the other end of this spectrum: those working to implement border controls.

In relation to the increasing bureaucratization of the refugee sector discussed earlier, two overarching issues are raised. Firstly, that many responsibilities are diminished by the need to be "expert" in areas beyond that for which you are trained. This has potential to de-professionalising of expertise, and deflect from the role one is required to deliver, leading also to the likelihood of overworking. Secondly, attempting to develop lay knowledge of complex legal systems opens potential avenues for misinterpretation and thus misinformation. Not only would such outcomes potentially put the service user at risk of relying on incorrect information, but places the practitioner at risk of disqualification if found to have done so. And yet, as was evident throughout the duration of this project, access to legal information was diminishing across all three countries. Sweden had been the only one of the three case study countries which had previously embedded legal support prior to the substantive interview, and example of best practice. However, capacity reduced in the aftermath of the increase of asylum applications in 2016. In Britain and Denmark, dispersal and destitution practices meant access to legal expertise was spatially determined. In short, as the laws became more restrictive and more expansive in a relatively short time, they have become more difficult to gain clear information about for people seeking asylum 
as well as for practitioners. The outcome is that other roles can be 'watered down" in what they are able to do, as any asylum case is reliant on legal support to navigate the system ${ }^{6}$.

The impacts of these variable issues can be vast, and as this article develops many of the symptoms will be recognisable in practitioner responses. However, given this project has been situated in grounded theory (Charmaz 2003), rather than apply such symptoms or categories, I instead theme common experiences in relation to broader social and structural conditions. It is here that my key argument lies: that although various impacts of working with refugee groups are well recognised, the punitive turn toward migrants generally and refugees and people seeking asylum specifically negatively impacts the way in which practitioners across many fields can do their jobs. As responses from participants demonstrate, barriers to effective support provision have been exacerbated by policies and laws which have worked to create hostile environments for migrants in the aftermath of the refugee reception crisis. As research undertaken during the contemporary Covid pandemic is already evidencing, the sector can slip into crisis when faced with more compounding external problems, including even further decreases in financial support (thus a potential sector squeeze on support provision), increased barriers to resources, and threats to refugee children's wellbeing. (Nisanci et al. 2020).

\section{Conclusions}

Harsh internal border regimes rely on increasing restrictions of movement, welfare, civil liberties and, in the context of immigration detention, liberty itself. Whether described as "hostile environments" (Theresa May 2012 in Canning 2017), "enhanced motivation techniques" (Inger Støjberg, see Suárez-Krabbe et al. 2018) or "degradation by design" (Canning 2019b), there is little doubt that increasingly punitive policies and laws have embedded harsher living conditions for migrants in Northern Europe. However, the implications of such environments stretch much further across society.

This article outlines the impacts of these restrictions on various forms of practitioners: support workers, psychologists, lawyers, social workers, detention custody officers and advocacy and support workers. However, despite the range of roles there are clear correlating experiences highlighted by those working with refugee groups. Some relate to well established fields of research, including vicarious trauma, secondary trauma, burnout and compassion fatigue. Yet as we can see, there are indications that intensified internalised bordering can reduce the ability of practitioners to exercise their professional roles effectively. Laws favouring reductions in family reunification rights impact on the ability of those whose families are "stuck" at borders to concentrate on (for example) psychological interventions or therapies relating to previous traumas. Dispersal policies or remote asylum centres make it difficult for practitioners to reach groups who live on the peripheries, or are moved whilst undertaking therapeutic courses or support. Poverty and destitution make it more difficult for people to access central practitioner spaces. Reductions in the availability of legal support add further cases to lawyers, reducing capacity for some to engage as fully as they otherwise would choose to.

The implications of this are threefold. Firstly, practitioners can experience negative emotional impacts as the conditions under which their service user group deteriorate: an issue inherent to increased hostilities for migrants. Secondly, people are experiencing a sense of deprofessionalisation and powerlessness in their work. Lastly, practitioners who feel they are over-stretched or "managing expectations" may be less able to engage with

\footnotetext{
6 In the UK, it is illegal to give legal advice without a relevant legal qualification. As an intervention in this issue, and to ensure that people seeking asylum had access to basic level information about the asylum system, Right to Remain have developed the Right to Remain Toolkit, which outlines the process and directs to relevant law without actually giving legal advice. In 2018, Lisa Matthews and I expanded this intervention to develop the Right to Remain Asylum Navigation Board. This was produced modelled on a board game but without being a game, and distributed to more than 100 organisations and individuals. In 2020, we reproduced this as an online version in response to the COVID-19 pandemic. Further information can be found here: https:/ / righttoremain.org.uk/brand-new-asylum-navigation-boards / (accessed on 27 May 2020) and the online version found here: https:/ /righttoremain.org.uk/asylum-navigation-board/ (accessed on 27 May 2020).
} 
the complexities of refugee groups, even with the best will in the world. This in itself in disenfranchising for people working in this field.

This phenomenon, I argue, creates a cyclical environment: socio-political hostilities against migrant groups (broadly, but here people seeking asylum specifically) compound already difficult working conditions for practitioners in this area. In turn, impacts on practitioners have potential for negatively affecting the people they support, thus disempowering a group which is already recognised as being disproportionally affected by violence, conflict and previous trauma.

Funding: This project was funded by the Economic and Social Research Council, grant number ES/NO16718/1.

Institutional Review Board Statement: This project was reviewed and ethical clearance granted by the Open University Human Research Ethics Committee (HREC) in June 2016. Guidance followed the British Society of Criminology and British Sociological Association guidance for ethical research with human subjects, as well as the Open University ethics guidance.

Informed Consent Statement: Informed consent was obtained from all subjects included in the study.

Conflicts of Interest: The author declares no conflict of interest.

\section{References}

Aas, Katja Franko, and Mary Bosworth, eds. 2013. The Borders of Punishment: Migration, Citizenship and Social Exclusion. Oxford: Oxford University Press.

Abdelhady, Dalia, Nina Gren, and Martin Joormann. 2020. Introduction. In Refugees and the Violence of Welfare Bureaucracies in Northern Europe. Edited by Dalia Abdelhady, Nina Gren and Martin Joormann. Manchester: Manchester University Press.

Adams, Richard E., Joesph A. Boscarino, and Charles R. Figlet. 2006. Compassion Fatigue and Psychological Distress among Social Workers: A Validation Study. American Journal of Orthospsychiatry 1: 103-8. [CrossRef] [PubMed]

Aliverti, Ana. 2012. Making People Criminal: The Role of the Criminal Law in Immigration Enforcement. Theoretical Criminology 16: 417-34. [CrossRef]

Canning, Victoria. 2013. Illusions of Freedom: The Paradox of Border Confinement, Oxford University Border Criminologies. Available online: http:/ / bordercriminologies.law.ox.ac.uk/illusions-of-freedom/ (accessed on 9 February 2021).

Canning, Victoria. 2017. Gendered Harm and Structural Violence in the British Asylum System. Oxon: Routledge.

Canning, Victoria. 2018. Zemiology at the Border. In Zemiology: Reconnecting Crime and Social Harm. Edited by Avi Boukli and Justin Kotzé. Basingstoke: Palgrave Macmillan.

Canning, Victoria. 2019a. Reimagining Refugee Rights: Addressing Asylum Harms in Britain, Denmark and Sweden, Migration and Mobilities Bristol. Available online: http:/ / www.statewatch.org/news/2019/mar/uk-dk-se-reimagining-refugee-rights-asylumharms-3-19.pdf (accessed on 9 February 2021).

Canning, Victoria. 2019b. Degradation by Design: Women Seeking Asylum in Northern Europe. Race E Class 61: 46-63.

Canning, Victoria. 2020a. Corrosive Control: State-Corporate and Gendered Harm in Bordered Britain. Critical Criminology 28: 259-75. [CrossRef]

Canning, Victoria. 2020b. Bureaucratised Banality: Asylum and Immobility in Britain, Denmark and Sweden. In Refugees and the Violence of Welfare Bureaucracies in northern Europe. Edited by Dalia Abdelhady, Nina Gren and Martin Joormann. Manchester: Manchester University Press.

Canning, Victoria. 2021. The Confinement Continuum: Sensing and Unease in Danish Asylum and Immigration Detention Centres. In Sensory Penalities. Edited by Kate Herrity, Bethany Schmidt and Jason Warr. Bingley: Emerald Publishing.

Baillot, Helen, Sharon Cowan, and Vanessa E. Munro. 2014. Reason to Disbelieve: Evaluating the Rape Claims of Women Seeking Asylum in the UK. International Journal of Law in Context 10: 105-39. [CrossRef]

Baillot, Helen, and Elaine Connelly. 2018. Women Seeking Asylum: Safe from Violence in the UK? Available online: http://www. asaproject.org/uploads/Safe_from_violence_in_the_UK._ASAP-RC_report_pdf (accessed on 9 April 2020).

Barker, Vanessa. 2018. Nordic Nationalism and Penal Order: Walling the Welfare State. Oxon: Routledge.

Barrington, Allysa J., and Jane Shakespeare-Finch. 2013. Working with refugee survivors of torture and trauma: An opportunity for vicarious post-traumatic growth. Counselling Psychology Quarterly 26: 89-105. [CrossRef]

Bögner, Diana, Chris Brewin, and Jane Herlihy. 2010. Refugees' Experiences of Home Office Interviews: A Qualitative Study on the Disclosure of Sensitive Personal Information. Journal of Ethnic Migration Studies 36: 519-35. [CrossRef]

Charmaz, Kathy. 2003. Qualitative Interviewing and Grounded Theory Analysis. In Inside Interviewing: New Lenses, New Concerns. Edited by James A. Holstein and Jaber F. Gubrium. London: Sage.

Clante Bendixen, Michaela. 2019. New Restrictions in the Finance Act 2019, Refugee Welcome Denmark. Available online: http: //refugees.dk/en/news/2018/december/new-restrictions-for-refugees-in-the-finance-act-2019/ (accessed on 15 February 2019).

Delamont, Sara. 2003. Feminist Sociology. London: Sage. 
Denzin, Norman K. 2008. Emancipatory Discourses and the Ethics and Politics of Interpretation. In Collecting and Interpreting Qualitative Materials. Edited by Norman K. Denzin and Yvonna S. Lincoln. London: Sage.

El-Enany, Nadine. 2020. Bordering Britain: Law, Race and Empire. Manchester: Manchester University Press.

Emejulu, Akwugu, and Leah Bassel. 2017. Women of Colour's Anti-Austerity Activism. In The Violence of Austerity. Edited by Vickie Cooper and David Whyte. London: Pluto Press, pp. 117-23.

Eule, Tobias G., Lisa Marie Borelli, Annika Lindberg, and Anna Wyss. 2018. Migrants before the Law: Contested Migration Control in Europe. Switzerland: Palgrave Macmillan.

European Commision. 2021. Denmark: Lowest Number of Asylum Seekers Ever, Europa. Available online: https:/ / ec.europa.eu/ migrant-integration/news/denmark-lowest-number-of-asylum-seekers-ever (accessed on 28 January 2021).

Fairclough, Norman, Jane Mulderrig, and Ruth Wodak. 2011. Critical Discourse Analysis. In Discourse Studies. A multidisciplinary Introduction. Edited by Teun A. Van Dijk. London: Sage, pp. 357-78.

Flyvbjerg, Bent. 2006. Five Misunderstandings about Case Study Research. Qualitative Inquiry 12: 219-45. [CrossRef]

Fog Olwig, Karen. 2012. Integration: Migrants and Refugees between Scandinavian Welfare Societies and Family Relations. In Migration, Family and the Welfare State: Integrating Migrants in Scandinavia. Edited by Karen Fog Olwig, Birgitte Romme Larsen and Mikkel Rytter. Oxon: Routledge.

Follette, Melanie P., and Victoria M. Duckworth. 2012. Retraumatisation: Assessment, Treatment and Prevention. New York: Routledge.

Galek, Kathleen, Kevin J. Flannelly, Paul B. Greene, and Taryn Kudler. 2002. Burnout, Secondary Traumatic Stress, and Social Support. Pastoral Psychology 60: 633-49. [CrossRef]

Girma, Marchu, Sophie Radice, Natasha Tsangarides, and Natasha Walter. 2014. Detained: Women Asylum Seekers Locked Up in the UK. London: Women for Refugee Women.

Jobe, Alison. 2009. Accessing Help and Services: Trafficking Survivor's Experiences in the United Kingdom. In (Re)Interpretations: The Shapes of Justice in Women's Experience. Edited by Lisa Dresdner and Laurel Peterson. Cambridge: Cambridge Scholars Press.

Joormann, Martin. 2017. A Temporary Asylum Law and Secret Legal Cases: The Swedish Migration Bureaucracy and Its Exceptions. Oxford Border Criminologies Blog. May 10. Available online: https://www.law.ox.ac.uk/research-subject-groups/centrecriminology/centreborder-criminologies/blog/2017/05/temporary-asylum (accessed on 27 May 2020).

Joormann, Martin. 2019. Legitimized Refugees-A Critical Investigation of Legitimacy Claims within the Precedents of Swedish Asylum Law. Ph.D. thesis, Lund University, Lund, Sweden.

Khosravi, Shahram. 2018. Stolen Time, New Statesman. Radical Philosophy 2: 33-34.

Machin, David, and Andrea Mayr. 2015. Critical Discourse Analysis. London: Sage.

Mason, Jennifer. 2002. Qualitative Researching. London: Sage.

Mayblin, Lucy. 2019. Imagining asylum, governing asylum seekers: Complexity reduction and policy making in the UK home office. Migration Studies 7: 1-20. [CrossRef]

Migrant Rights Network. 2018. Know Your Rights: A Guide for Migrants. Available online: https://migrantsrights.org.uk/wpcontent/uploads/2018/03/Hostile-Environment-WEB-1.pdf (accessed on 8 January 2019).

Nisanci, Aslihan, Rumeysa Kahraman, Yusuf Alcelik, and Ulviyenur Kris. 2020. Working with Refugees during COVID-19: Social Worker Voices from Turkey. International Social Work 63: 685-90. [CrossRef]

Pross, Christian. 2006. Burnout, Vicarious Traumatisation and its Prevention. Torture 16: 1-9. [PubMed]

Ray, Susan L., Carol Wong, Dawn White, and Kimberly Heaslip. 2013. Compassion Satisfaction, Compassion Fatigue, Work Life Conditions, and Burnout among Frontline Mental Health Care Professionals. Traumatology 19: 255-67. [CrossRef]

Rønning, Line, Jocelyn Blumberg, and Jesper Dammeyer. 2020. Vicarious Traumatisation in Lawyers Working with Traumatised Asylum Seekers: A Pilot Study, Psychiatry, Psychology and Law. Available online: https://doi.org/10.1080/13218719.2020.1742238 (accessed on 9 February 2021).

Suárez-Krabbe, Julia, Annika Lindberg, and Jose Arce. 2018. Stop Killing Us Slowly: A Research Report on the Motivation Enhancement Measures and Criminalisation of Rejected Asylum Seekers in Denmark. Roskilde: Freedom of Movement Research Collective.

Taylor, Diane. 2018. Homeless Charity Aided Deportation Patrols in Search for Rough Sleepers. The Guardian. March 5. Available online: https:/ / www.theguardian.com/uk-news/2018/mar/05/st-mungos-homeless-charity-helped-target-roughsleepers-to-deport (accessed on 27 May 2020).

The Local Denmark. 2018. Denmark's Anti-Begging Law Only Convicted Foreigners: Report. The Local. July 4. Available online: https://www.thelocal.dk/20180704/denmarks-anti-begging-law-only-convicted-against-foreigners-report (accessed on 27 May 2020).

National Health Service (NHS). 2015. The National Health Service (Charges to Overseas Visitors) Regulations 2015. Available online: http:/ / www.legislation.gov.uk/uksi/2015/238/contents/made (accessed on 27 May 2020). 